\title{
High-Added Value Materials Production from OMW: A Technical and Economical Optimization
}

\author{
E. C. Arvaniti, ${ }^{1,2}$ D. P. Zagklis, ${ }^{1,2}$ V. G. Papadakis, ${ }^{3}$ and C. A. Paraskeva ${ }^{1,2}$ \\ ${ }^{1}$ Institute of Chemical Engineering and High Temperature Chemical Processes, Foundation for Research and \\ Technology-Hellas (FORTH/ICE-HT), Stadiou Street, Platani, 26504 Patras, Greece \\ ${ }^{2}$ Department of Chemical Engineering, University of Patras, 26504 Patras, Greece \\ ${ }^{3}$ Department of Environmental \& Natural Resources Management, University of Western Greece, 30100 Agrinio, Greece \\ Correspondence should be addressed to C. A. Paraskeva, takisp@chemeng.upatras.gr
}

Received 17 October 2011; Revised 3 February 2012; Accepted 6 February 2012

Academic Editor: Licínio M. Gando-Ferreira

Copyright () 2012 E. C. Arvaniti et al. This is an open access article distributed under the Creative Commons Attribution License, which permits unrestricted use, distribution, and reproduction in any medium, provided the original work is properly cited.

The extraction of olive oil generates huge quantities of solids and of high organic wastewaters with toxic constituents that have a great impact on land and water environments. Based on a membrane process, authors proposed an alternative method for treatment of olive mill wastewaters (OMWs). In the present paper, a technoeconomic analysis for the implementation of the proposed method in the entire Region of Western Greece (RWG) is presented. This paper takes into account fixed and operational costs, costs for the infrastructure, equipment, land, maintenance, and so forth, considering the treatment of 50,000 tons per harvesting period in the area of RWG. The study showed that the establishment of only one central treatment manufacture could reduce the uncontrolled disposal of OMW. Exploitation of the isolated fractions as manure in fertilizers (nutrients components) or as components in ecological herbicides (phenolics) can depreciate the total cost in a period of about five years.

\section{Introduction}

Olive oil production has roughly increased worldwide in the last decades. Mediterranean countries produce $95 \%$ of the total world production of olive oil [1]. The largest producers of olive oil are Spain (42\% of world production in 2007), Italy (19\%), and Greece (13\%), followed by Tunisia, Syria, Morocco and Turkey [1]. This makes olive oil extraction an agroindustrial activity of vital economic significance to many Mediterranean countries.

Despite the economic benefit, olive oil production is unfortunately associated with the generation of large quantities of wastewaters (olive mill wastewater-OMW) [2] and solid wastes, whose management, treatment, and safe disposal raise serious environmental concerns. A typical olive mill is currently producing on the average some 1,000 metric tons of toxic liquid wastes per harvesting season [3]. Olive mill wastewater (OMW) is a mixture of nutritious agents appropriate for fertilizing or animal feed (inorganic salts, proteins, fat substances, etc.), as well as phenolics, tannins, and other substances with phytotoxic action. The characteristic properties of OMW include its dark color, characteristic odor, acidic $\mathrm{pH}$, and high organic content mainly composed of classes of pollutants such as phenolics that may exhibit antimicrobial, ecotoxic, and phytotoxic properties $[4,5]$. The BOD (biochemical oxygen demand) and COD (chemical oxygen demand) of these wastewaters are such that the environmental damage from each olive mill is serious in touristic and agricultural Mediterranean regions. Due to the high organic load of OMW, it may contribute significantly to eutrophication of recipients in which fluid exchange rates are low (closed gulfs, estuaries, lakes, etc.) [6-8]. An additional adverse impact of OMW on the environment is the aesthetic degradation caused by its strong odour and dark coloration. Problems arise also from the fact that olive oil production is seasonal, and so the treatment process should be flexible enough to operate in a noncontinuous mode; otherwise storage of the wastewater will be required [9]. Moreover, the olive mills are small enterprises, mostly family businesses, scattered around the olive production areas, making individual on-site treatment options unaffordable. Therefore, it is not surprising that OMW treatment has received enormous attention over the past several years, and various 
decontamination technologies based on biological, advanced oxidation, chemical and separation processes have been proposed by several research groups as summarized in a recent review article [10].

OMW composition depends significantly on the olive type and the treatment procedure. Thus, it may be different from one region to another and among the olive mills of the same region. In general, these wastewaters contain the largest fraction of water-soluble components of olives, solid organics, and fats and lipids. The majority of olive oil mills in Greece use the three-phase decanter systems that produce huge quantities of liquid wastes. The solids (olive kernels) are sold to olive core companies to produce the well-known olive core oil which is of less nutritious value. The liquid OMW is produced by the liquid fraction of the olive juice and the water used during the different phases of olive mill processing. Essentially, it is an aqueous vegetable extract, containing a number of substances such as sugars, nitrogenous compounds, organic acids, polyalcohols, polyphenols, and oil residue.

It should be noted that the production of olive oil is a natural process, and thus the olive mill wastewater does not contain other substances that are highly toxic, such as heavy metals and synthetic organic compounds. The phenolic components are the various phenolic acids (caffeic, protocatechuic, $\alpha$-hydroxycinnamic, vanillic), flavonoids, anthocyanes, and seleoprotein. Phenolics and tannins are the main components with phytotoxic action. The main components with nutritious value are hydrocarbons, inorganic salts, and so forth, depending on the application (animal feed or fertilizers).

A combination of appropriate physicochemical processes can be applied for the fractionation of the wastes into useful isolated by-products as fertilizers, herbicides, and so forth. It must be added that almost in the same season of olive harvest, the farmers spray the land under the olive trees with herbicides for weed control. These strong chemicals affect the environment negatively, putting in high risk the health of the farmers; they are also accumulated and may be introduced in the food chain. On the contrary, the development of an environmentally friendly herbicide as a fraction from OMW will offer an ecological solution to this severe problem. Thus, two targets could be achieved simultaneously; a sustainable solution for the disposal of olive mill wastes and the production of alternative ecological herbicides and other useful by-products.

Coping with the environmental pollution problem, created by wastes from olive mills, presents large difficulties, mainly due to the high cost of the treatment of residual waters using the various systems proposed so far. In recent years, only in Italy more than 100 companies have proposed relevant systems, but none of them constitutes a practical and low-priced solution to the problem. Thus, the present situation is more or less the same as in the past: these wastes are led to large pits or discharged into the sea, lakes, rivers, and so forth, causing destructive environmental implications. As the fixed cost for installing such systems seems not decreasing, a profit from possible useful by-products could contribute significantly to the problem solution. The present work is oriented to this direction.

The management of OMW has been extensively investigated, and some extensive and detailed reviews, which focus mainly on its management, have been recently published [10-12]. Provided that the fixed cost for the installation of OMW treatment systems seems to be in-elastic, operational cost reduction may be attained through the exploitation of the waste by-products. The proposed separation techniques (prefiltration (filter press), ultrafiltration (UF), nanofiltration (NF), and reverse osmosis (RO)) of the OMW treatment using membranes filtration have already been presented in previous works by the authors $[3,13]$. The idea is based on the exploitation of membrane filtration fractions to reduce the high fixed costs in order for a viable and sustainable solution to be obtained. In those studies a pilot plant was developed in an olive mill (1,000t/yr) operating in Achaia region (Patras, Greece) during a full harvesting period [3, 13], and a technoeconomical solution was presented for the implementation of the proposed method in each olive mill enterprise. However, private olive mills are small family businesses and cannot afford the costs of the treatment of their own wastewaters. Thus, in the present study three new options were taken into account. The first refers to the creation of an OMW treatment unit in every 5-6 adjacent olive mills, and the second refers to the development of a mobile unit that can pass across the olive mill units to treat their wastes. The third proposed method, which sounds interesting for the local olive mill industry, was the development of a central unit (50,000 t/yr) which can handle all olive mill wastewaters from all olive mills, in the prefecture of Achaia. The last idea was evaluated as a successful solution and can be applied also in other areas, which face the same environmental problems. The feasibility-exploitation study for the third suggested method is presented in detail and shows that indeed the depreciation of the expensive investment can be done in a short period of time.

\section{Proposed Method}

Ultrafiltration (UF), nanofiltration (NF), and/or reverse osmosis (RO) (Figure 1) can be used for isolation of OMW fractions. These methods were investigated in previous work $[3,13]$ through a systematic parametric study changing accordingly the operational parameters, such as temperature, pressure, and initial $\mathrm{pH}$ of different source of OMW, type and size of membranes (pore diameter), and so forth, in order to obtain a higher separation of toxic fraction from the nutritious one. Different fractions were derived from the entire process: a nutritious fraction as pre- or post UF concentrate containing the larger components of the solution in terms of molecular size, a toxic fraction as NF and/or RO concentrate containing the main part of phenolics (ecological herbicide), a plant nutritious fraction as RO permeate containing the inorganic salts (fertilizer), and almost pure water for recycling/irrigation or for free disposal to aqueous acceptors (lakes, rivers, or sea).

One thing that is of primary importance is that UF provides a "clean" solution appropriate to feed next treatment 


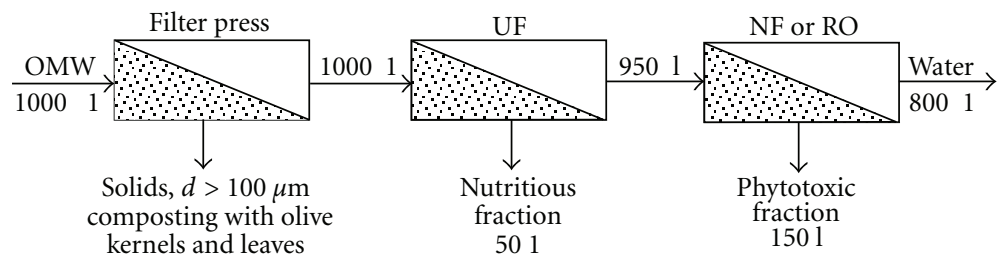

FIGURE 1: Separation structure of the flowsheet using ultrafiltration (UF), nanofiltration (NF), and/or reverse osmosis (RO) techniques.

TABle 1: Physicochemical characterization of fractions of the various treatment stages.

\begin{tabular}{|c|c|c|c|c|c|c|c|c|}
\hline \multirow{2}{*}{ Parameter } & \multirow{2}{*}{ Raw } & \multirow{2}{*}{ Perm prefilter $=$ feed UF } & \multicolumn{2}{|c|}{ Ultrafiltration } & \multicolumn{2}{|c|}{ Nanofiltration } & \multicolumn{2}{|c|}{ Reverse osmosis } \\
\hline & & & Conc & $\begin{array}{c}\text { Perm }=\text { feed } \\
\text { NF }\end{array}$ & Conc & $\begin{array}{c}\text { Perm }=\text { feed } \\
\text { RO2 }\end{array}$ & Conc & Perm \\
\hline Salinity, \% & 0.66 & 0.66 & 0.67 & 0.59 & 1.11 & 0.01 & 0.02 & 0.0 \\
\hline TSS, g/L & 21.5 & 18.56 & 46.98 & 2.36 & 5.32 & 0 & 0.0 & 0.0 \\
\hline t-COD, g/L & 97.32 & 92.9 & 127.19 & 94.88 & 156.44 & 1 & 9.1 & 0.2 \\
\hline d-COD, g/L & 85.68 & 72.24 & 61.92 & 77.64 & 131.32 & 1 & 7.56 & 0.16 \\
\hline Carbohydrates, g/L & 28.75 & 20.51 & 18.8 & 24.1 & 51.827 & 0.310 & 3.2 & 0.1 \\
\hline Phenolics, g/L & 5.91 & 5.08 & 4.16 & 5.04 & 10.6 & 0.1 & 0.9 & 0.01 \\
\hline
\end{tabular}

processes (NF or RO). UF alone cannot isolate individual fractions (in terms of only toxic or only nutrient solutions) but without UF we cannot proceed for further purification with the NF and/or RO. Physicochemical analysis of the collected compounds in pretreatment procedure, ultrafiltration, nanofiltration, and reverse osmosis, is shown in Table 1 . The permeate stream from each unit is used as feed stream for the next membrane unit. Treatment can be terminated after the implication of NF or RO since the permeate stream of NF (see Table 1) shows that the produced water can be safely used as irrigation water or to be disposed safely to aqueous receptors.

\section{Technoeconomical Analysis}

3.1. Proposed Technical Solution. Based on the suggested methods that should be followed for the efficient separation of the "nutritious" from the "toxic" fraction, an optimum, technical, and economical design of the process at industrial level was carried out. The target is a technically acceptable solution at the possible lowest fixed and operational cost. This goal was succeeded by applying a conceptual design to find the best process and estimate the optimum design conditions. After definition of the operational parameters, the process flowchart was constructed via a hierarchy of design decisions, namely, structure of input-output, recycling, separation, and thermal integration [3].

3.2. Preliminary Design. The technoeconomical study for the establishment of OMW treatment plant was done for the Region of Western Greece. The number of all olive mills for three regions (prefectures of Achaia, Ilia, Aitoloakarnania) was recorded. There were three alternative scenarios: (a) the establishment of a central operation plant (e.g., one per region or a greater area), where OMW would be carried by trucks. Profit will be made by the production of high-valued by-products. (b) The second was the establishment of more than one lower potential operation plants (one per five olive mills). In this case the transport expenses are diminished. (c) The third was a mobile OMW treatment unit.

The third case was rejected as olive mills work seasonally in the same period, and this constitutes several technical complications (size of the tanks on the truck, disposal of concentrated fractions, etc.). Therefore, the study was concentrated on the other two solutions. Taking into account the location, the distance and the number of olive mills per region, the cost and the time of transportation, the establishment of a central OMW treatment plant per region was considered to be more appropriate from both technical and economical point of view.

The most serious problems that could be faced are (a) the authorities permission for disposal and sale of byproducts from the above OMW treatment that may be used as ecological herbicides and fertilizers for agriculture and (b) the possible denial of olive mills owners to bear the cost of their OMW storage, despite the fact that they are obliged to perform a kind of treatment.

Four actions took place (a) The first one was mapping of the olive mills that are active in Achaia and Ilia regions as first indicative areas, preliminary study of the cost and transferring time of OMW in a central place per region (e.g., Patras Industrial Area). (b) The second was examination of the legal framework that concerns the approval and sale of ecological herbicides and fertilizers for agriculture in Greek and European market. (c) The third was examination of the market demand for ecological herbicides and fertilizers for agriculture in the trade union and end users. (d) The last one was the examination of the use of OMW components for the production of biodiesel, bioplastic, or other alternative products of high value. 
3.3. Case Study: Region of Western Greece. Region of Western Greece is the suggested area for the establishment of OMW pilot plant. It is an area with a tradition in olive oil production. Furthermore, Achaia is adjoining to several olive oil production areas. There are 50 active olive mills in Achaia and surroundings. Taking into account the distances among olive mills, the transportation costs (fuel and service expenses) are estimated to $0.25 € / \mathrm{km}$. All the olive mills are gathered close to Patras Industrial Area. There are available areas and the necessary infrastructures for the establishment of an OMW treatment unit. Investments incentives and tax reductions have been given to the Patras Industrial Area for the industrial development in Achaia, which increases depreciation of the investment. Therefore, the establishment of a central plant in the Industrial Area of Patras is suggested in the present work.

3.4. Capacity and Settlement of Production Process. The OMW treatment unit is designed to operate continuously 24 h/day, 7 days/week, 7 months/yr (period during oil production from October till April), 210 days/yr. The unit would have a capacity over 50,000 t/yr and will serve a number of about 50 olive mills of the surrounded area (an average production of 1,000 t/yr OMW per olive mill will give an average capacity of the unit which arises up to 50,000 tn/yr).

The technoeconomical study for the establishment of an OMW treatment unit has the following approximate characteristics:

feed to the system: OMW,

feed flow rate: $10,000 \mathrm{~L} / \mathrm{h}(50,000 \mathrm{t} / \mathrm{yr})$,

permeate flow rate: $8,000 \mathrm{~L} / \mathrm{h}$,

working temperature: $20-30^{\circ} \mathrm{C}$,

working pressure: UF: 4 bar, RO: 70 bar max,

COD removal: $99.5 \%$,

grease substances removal: 99.99\%,

dry matter removal: 99.5\%,

UF system: feed pump, protective cartridge filter, loop pump, ceramic elements, structure, valves and piping, electrical part,

RO system: feed pump, protective cartridge filter, high pressure pump, filtering elements, structure, valves and piping, electrical part,

utilities,

air: 5/6 bar,

Water for membrane cleaning: demineralized/ soft or osmotized,

power supply: $380 \mathrm{~V}, 50 \mathrm{~Hz}$, three phases.

3.5. Fixed Cost and Initial Operating Capital. The establishment of an industrial unit demands costs for the designing study, for the building site purchasing and its modulation, for the purchasing and establishment of the equipment, and so forth. Cost for UF and RO systems, installed on site, feed tanks, any storage or peripheral tanks, prefilter system, pumps and piping, hydraulic, electrical, and pneumatic connections, computers, vehicles, lab and office equipment, security equipment, offices, laboratories, storehouse and auxiliary equipment, land, and so forth are presented in Table 2. The method for ratio capacity units [14] has been used to estimate the fixed cost, initial networking capital, and investment capital. This method is based on the equation:

$$
C_{2}=C_{1} \cdot\left(\frac{Q_{2}}{Q_{1}}\right)^{n},
$$

where $Q_{1}, Q_{2}$ : capacity, $C_{1}$ : fixed cost for $Q_{1}, C_{2}$ : fixed cost for $Q_{2}$, and $n$ parameter. For chemical industry exponent $n$ is equal to $2 / 3$, and the method is called method of $2 / 3$.

A cost for the biodynamic experiments is calculated and included in the fixed cost. These experiments are needed for the investigation of the impact that produced herbicides, fertilizers, and water have on the human health.

3.6. Operational Cost. The operational cost $(€ / y r)$ includes a number of elements that are given in Table 3 . In the same table information is given for the approximation of the cost of some of the elements in operational cost using coefficients. It is important to mention that when the taxes are negative (in the present case below 2,800 t/yr), the operational cost before taxes $\left(\mathrm{OC}^{\prime}\right)$ (Table 3 ) is taken into account. For the capacity of $50,000 \mathrm{t} / \mathrm{yr}$, labor cost is about $28.79 \%$ of the operational cost and is the maximum percentage while the cost for the raw material (OMW) is zero. This percentage changes according to the capacity. Thus, if the capacity changes from $50,000 \mathrm{t} / \mathrm{yr}$ to $2,800 \mathrm{t} / \mathrm{yr}$, then the depreciation cost reaches $5 \%$ of the operational cost while the labor cost drops at $4.29 \%$ of the operational cost. In any case the cost of OMW is zero because mill owners like to get rid of them. Furthermore, an income is more possible to arise from the OMW if the owners of the olive mill need to treat their wastes before disposing them to the soil; in order to avoid a penalty from the authorities.

A cost benefit analysis is presented in Figures 2 and 3 for two different capacities. Figure 4 shows the revenues of the investment for a capacity of 50,000 t/yr, which exhibits operational cost. On the other hand when the unit works with a capacity of $1000 \mathrm{t} / \mathrm{yr}$, the operational cost is much higher than the revenues of the investment. Each element of the operational cost is changing according to the capacity changes. It has been calculated that in a capacity of 2,800 t/yr the revenues of the investment are equal to the operational cost.

\section{Economical Potential: Assessment of the Investment}

A production of $5 \%$ nutrition fraction which can be used as fertilizer and $15 \%$ of toxic fraction that can be used as herbicide can be expected. The rest is pure water which can be used for recycling and irrigation.

The value of the nutritious fraction, taking into account its concentration in nutritious components, (either as fertilizer or as animal feed integrator) is estimated to have an order of magnitude of $100 € / t$ UF concentrate that gives 250,000€/yr (data from AGRO). The value of the 
TABLE 2: Equipment, building, and operational costs for an OMW treatment unit of 50,000 t/yr capacity. Calculations of the fixed cost, initial networking capital cost, and investment capital cost in Euros.

\begin{tabular}{|c|c|}
\hline Equipment for capacity $Q 1=50,000 \mathrm{t} \mathrm{OMW} / \mathrm{yr}$ & Euro \\
\hline Purchase and establishment of basic equipment (UF and RO units, mechanical and electrical parts, etc.) & $1,000,000 €$ \\
\hline Auxiliary settlement, environmental protection system, and equipment maintenance department (lifetime: 10 years) & $78,000 €$ \\
\hline Substation (lifetime: 15 years) & $30,000 €$ \\
\hline Quality control laboratory equipment (lifetime: 10 years) & $21,000 €$ \\
\hline Transportation unit and equipment store (lifetime: 10 years) & $46,000 €$ \\
\hline 2 loading machines, clarks (lifetime: 10 years) & $30,000 €$ \\
\hline 5 vehicles for OMW collection_-product shell (lifetime: 10 years) & $105,000 €$ \\
\hline Safety equipment clothing (lifetime: 2 years) & $5,000 €$ \\
\hline Office equipment, PC, and furniture (lifetime: 10 years) & $30,000 €$ \\
\hline Total purchase and installation cost, CE1 & $1,345,000 €$ \\
\hline \multicolumn{2}{|l|}{ Buildings cost } \\
\hline Offices, laboratory, storage and building equipment & $240,000 €$ \\
\hline Fencing & $5,000 €$ \\
\hline Building site & $100,000 €$ \\
\hline Building total (depreciation in 25 years apart from building site) & $345,000 €$ \\
\hline General total (CE1 + building total) & $1,690,000 €$ \\
\hline Unexpectedly (10\% direct cost) & $169,000 €$ \\
\hline Fixed cost, $C_{1}$ (general total + unexpectedly) & $1,859,000 €$ \\
\hline Biodynamic experiments, $C_{2}$ & $1,000,000 €$ \\
\hline Total fixed cost, $C\left[C_{1}+C_{2}\right]$ & $2,859,000 €$ \\
\hline Initial networking capital cost, IC $[0.18 * C]$ & $334,620 €$ \\
\hline Investment capital cost $[C+\mathrm{IC}]$ & $3,193,620 €$ \\
\hline
\end{tabular}

TABLE 3: Operational costs for an OMW treatment unit of 50,000 t/yr capacity.

\begin{tabular}{lc}
\hline Operational cost & Euro/yr \\
\hline (1) Feedstock, cleaning chemicals $(114 € /$ day $)$ & $30,200 €$ \\
(2) Energy (UF: $260 \mathrm{~kW}$, RO: $90 \mathrm{~kW})(29.7 € / \mathrm{hr})$ & $149,700 €$ \\
(3) Labor costs & $329,000 €$ \\
(4) Maintenance $(0.05 * C)$ & $67,250 €$ \\
(5) Administration costs (usually 50\% labor costs) & $274,000 €$ \\
(6) Insurance (establishment and products) $[1 \% *$ & $13,450 €$ \\
C] & \\
(7) Depreciation $($ linear depreciation zero residual & $148,300 €$ \\
$\quad$ value) & $67,250 €$ \\
(8) Interest [0.05 $* C]$ & $63,750 €$ \\
(9) General costs & $1,142,900 €$ \\
Operational cost before taxes $\left(\mathrm{OC}^{\prime}\right)$ & $392,840 €$ \\
(10) Taxes $(\mathrm{T})\left[0.4 *\left(\mathrm{R}-\mathrm{OC}^{\prime}\right)\right]$ & $1,535,740 €$ \\
Operational cost after taxes $\left(\mathrm{OC}^{\prime \prime}\right)$ & \\
\hline
\end{tabular}

"toxic fraction" as herbicide is estimated as much higher (data from AGRO), due to the higher value of phytotoxic constituents (herbicides) in the market. Taking into account the concentration of the $\mathrm{RO}$ concentrate, a modest value of $250 € / \mathrm{t} \mathrm{RO}$ concentrate is estimated that gives about $1,875,000 € /$ yr.

Thus, an economical potential of $2,125,000 € / \mathrm{yr}$ is expected annually if the capacity is $50,000 \mathrm{t} / \mathrm{yr}$. Taking into account that taxes are $40 \%$, a net profit of $589,260 € / \mathrm{yr}$ is estimated. From the above analysis, the rate of return on investment, $i_{r}$, is estimated:

$$
i_{r}=\frac{K}{(C+\mathrm{IC})},
$$

where $K$ : the annual net profit, $C$ : total fixed cost, and IC: the initial working capital. Between two or more alternative investments the one with the highest $i_{r}$ will be chosen. When an investment is examined separately, the $i_{r}$ of the investment should be higher than a minimum acceptable rate of return that has been determined by the company (possibly the bank interest). This method does not take into account the time value of money.

Thus, $i_{r}=589,260 /(2,859,000 €+334,620 €) \times 100 \%=$ $18 \%$.

In Figure 4 the return of the investment has been plotted as a function of the capacity. As it can be seen from the diagram the capacity that the $i_{r}$ is zero is $2,800 \mathrm{t} / \mathrm{yr}$, and this is the breakeven point of the investment. This capacity corresponds to wastes from 2-3 typical olive mills, and thus 


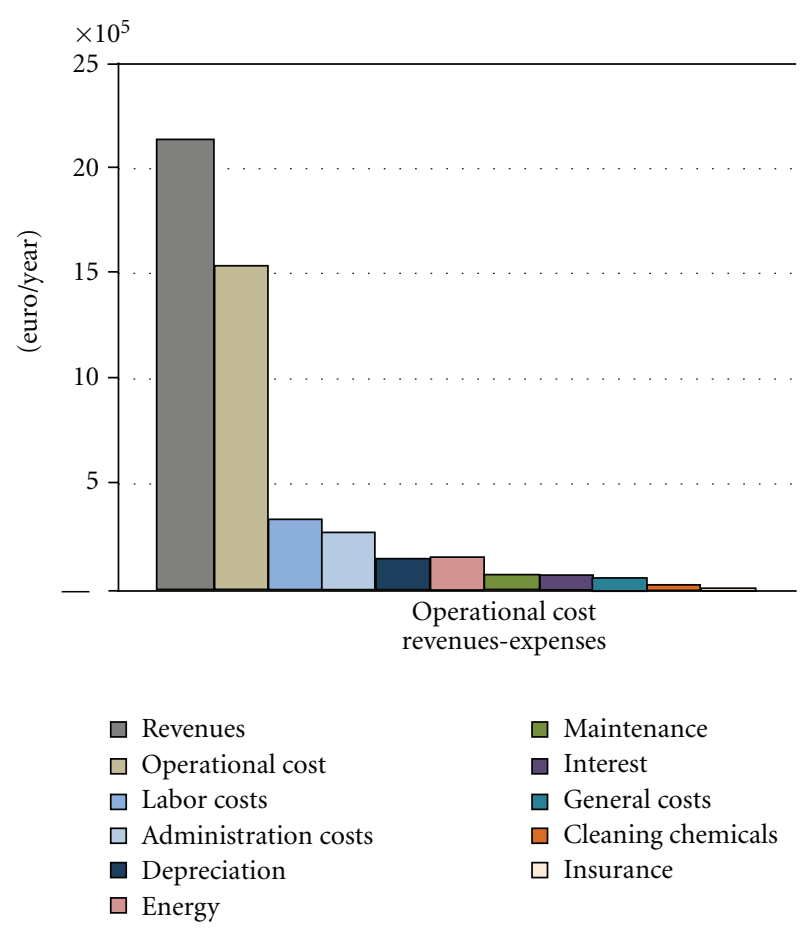

FIgURe 2: Cost-benefit analysis for a capacity of 50,000 t/yr.

when a plant is designed only at a local level in order to treat the OMW from 2-3 typical olive mills and less, it operates with deficits. Below this capacity the $i_{r}$ is negative. Above this value the $i_{r}$ is positive, and it does not increase proportionally to the capacity. For a capacity lower than $10,000 \mathrm{t} / \mathrm{yr}$ (capacity of 10 typical olive mills) the investment is not recommended to be undertaken as it gives a return on investment less than 5\% (which it is supposed as a current "safe" bank interest). For the targeted capacity of 50,000 t/yr (capacity of 50 typical olive mills) the return on investment is considered as very satisfactory (18\%).

The time needed to rebound the establishment capital cost from incomes during the operation period of the OMW treatment unit, that is, the mean payout period, $\tau$, is estimated as follows:

$$
\tau=\frac{(C+\text { IC })}{K} .
$$

The total cost of the investment can be replaced by the fixed cost, and the depreciation can be added to the net profit. Between two or more alternative investments the one with the lowest $\tau$ will be chosen. In Western Greece Region case, the mean payout period for the investment is estimated to $\tau=5.42$ years. This is a very encouraging result, taking into account that a rather low value for the toxic fraction was considered (only $250 € / \mathrm{t}$ ). The above result is characterized as positive and indicates to undertake the investment.

\section{Conclusions}

The management of produced OMW constitutes a longterm and particularly unsolved problem, because of their

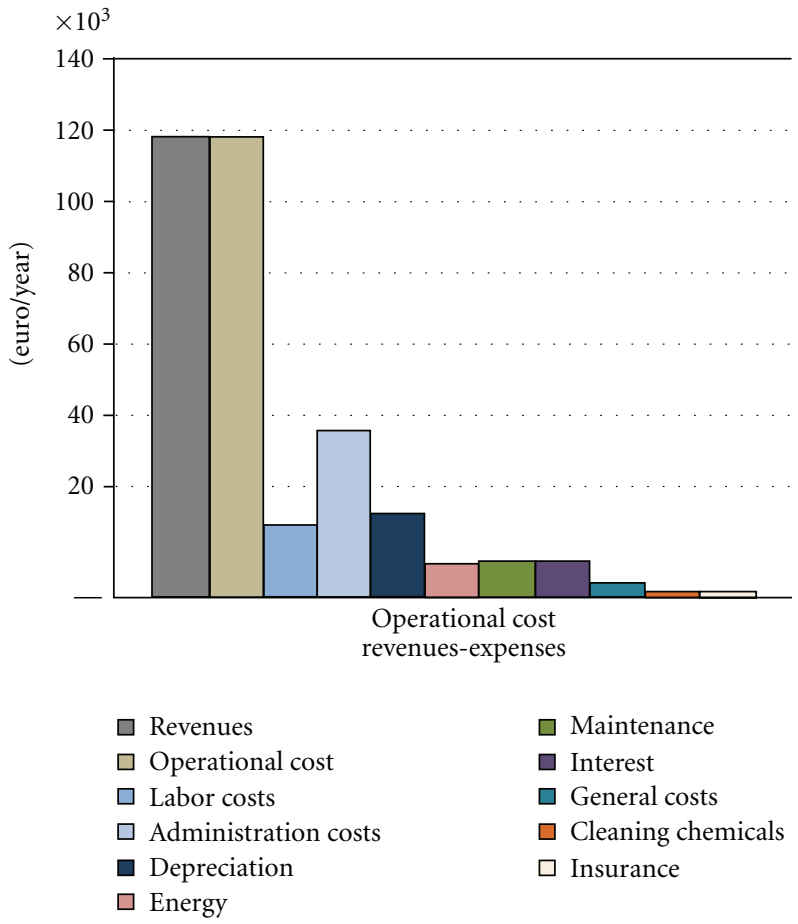

FIGURe 3: Cost-benefit analysis when the unit is working in a capacity of 2,800 t/yr (breakeven point).

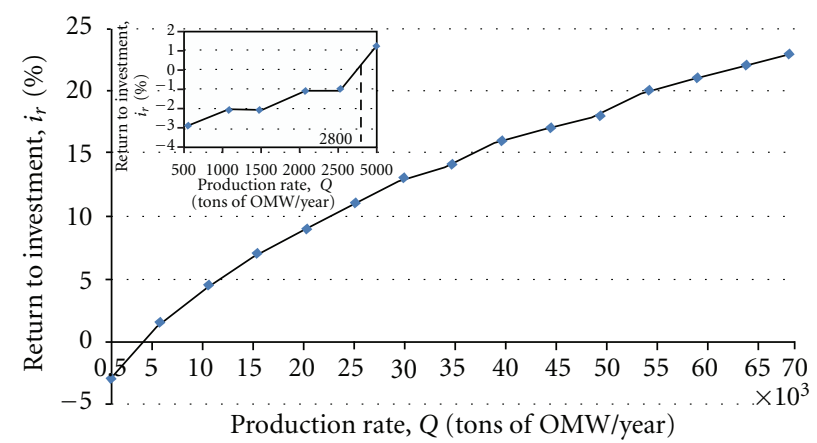

FIGURE 4: Return of the investment as a function of the capacity. Breakeven point $(2,800 \mathrm{t} / \mathrm{yr})$ of the investment when $i_{r}$ equals to zero.

high organic load, their particular physicochemical composition, the potentially toxic attributes, the intense of short time interval of production, and the high-cost investment requirements. The present work presents a technoeconomic analysis of the OMW treatment using membranes filtration. The idea of using membrane technology is presented by authors [13] in a previous work in which a new cost-effective system for complete exploitation of OMW is suggested, offering a viable solution to the problem of OMW disposal. A pilot plant was designed, constructed, and installed in a typical olive mill, where OMW quantities were treated at larger volumes. The efficiency of the proposed method for separation and exploitation of the OMW useful constituents was demonstrated. 
In the present work, a feasibility study of the proposed method at a regional level was performed, indicating very positive financial results for a future exploitation. The successful integration of this work establishes the basis for a complete and profitable solution of one of the most important Mediterranean environmental problems, providing as main achievements the following. (a) The first is the development of a new cost-effective system for complete exploitation of OMW, which offers a viable solution to the problem of OMW disposal. The introduction of the proposed new integrated technology reduces dramatically the environmental damage and provides a profitable alternative to the olive mills due to utilization of all by-products. (b) The second is the development and production of alternative ecological herbicides and other useful by-products. It is expected that these new products will be highly accepted from the farmers and will enhance the agriculture sustainability.

The rate of return on the investment is acceptable (18\%) for the targeted capacity of 50,000 t/yr (capacity of 50 typical olive mills), and the investment is considered viable. Nevertheless, when the capacity is 2,800 t/yr (breakeven point), the return of the investment is zero. Considering that this capacity corresponds to wastes from 2-3 typical olive mills, the investment is unaffordable for a plant that is designed only at a local level (2-3 typical olive mills and less). Moreover, the mean payout period can be considered as satisfactory, taking into account that the whole equipment of the investment is new, and the total cost of the investment has been considered; thus the depreciations have been added to the net profit. This is a very encouraging result, taking into account that a rather low value for the toxic fraction was also considered. The above result is characterized as positive and indicates to undertake the investment.

\section{Acknowledgment}

The authors wish to thank the European Commission for financial support for dissemination of their results under FP7-Regions-2009-1, STInno project (245405) and SWAM project (245427).

\section{References}

[1] M. A. Mohammad, "World and Syrian Trade in Olive Oil And Related Agricultural Policy," COMMODITY BRIEF No 11, 2009.

[2] N. Hytiris, I. E. Kapellakis, R. de la Roij, and K. P. Tsagarakis, "The potential use of olive mill sludge in solidification process," Resources, Conservation and Recycling, vol. 40, no. 2, pp. 129-139, 2004.

[3] C. A. Paraskeva, V. G. Papadakis, D. G. Kanellopoulou, P. G. Koutsoukos, and K. C. Angelopoulos, "Membrane filtration of olive mill wastewater and exploitation of its fractions," Water Environment Research, vol. 79, no. 4, pp. 421-429, 2007.

[4] J. Cegarra, C. Paredes, A. Roig, M. P. Bernal, and D. García, "Use of olive mill wastewater compost for crop production," International Biodeterioration and Biodegradation, vol. 38, no. 3-4, pp. 193-203, 1996.

[5] C. Paredes, J. Cegarra, A. Roig, M. A. Sánchez-Monedero, and M. P. Bernal, "Characterization of olive mill wastewater (alpechin) and its sludge for agricultural purposes," Bioresource Technology, vol. 67, no. 2, pp. 111-115, 1999.

[6] M. J. Paredes, E. Moreno, A. Ramos-Cormenzana, and J. Martinez, "Characteristics of soil after pollution with waste waters from olive oil extraction plants," Chemosphere, vol. 16, no. 7, pp. 1557-1564, 1987.

[7] M. DellaGreca, P. Monaco, G. Pinto, A. Pollio, L. Previtera, and F. Temussi, "Phytotoxicity of low-molecular-weight phenols from olive mill wastewaters," Bulletin of Environmental Contamination and Toxicology, vol. 67, no. 3, pp. 352-359, 2001.

[8] G. Rana, M. Rinaldi, and M. Introna, "Volatilisation of substances alter spreading olive oil waste water on the soil in a Mediterranean environment," Agriculture, Ecosystems \& Environment, vol. 96, pp. 49-58, 2003.

[9] P. Paraskeva and E. Diamadopoulos, "Technologies for olive mill wastewater (OMW) treatment: a review," Journal of Chemical Technology and Biotechnology, vol. 81, no. 9, pp. 1475-1485, 2006.

[10] M. Niaounakis and C. P. Halvadakis, Olive-Mill Waste Management: Literature Review and Patent Survey, TypothitoGeorge Dardanos Publications, Athens, Greece, 2006.

[11] A. Roig, M. L. Cayuela, and M. A. Sánchez-Monedero, "An overview on olive mill wastes and their valorisation methods," Waste Management, vol. 26, no. 9, pp. 960-969, 2006.

[12] N. Azbar, A. Bayram, A. Filibeli, A. Muezzinoglu, F. Sengul, and A. Ozer, "A review of waste management options in olive oil production," Critical Reviews in Environmental Science and Technology, vol. 34, no. 3, pp. 209-247, 2004.

[13] C. A. Paraskeva, V. G. Papadakis, E. Tsarouhi, D. G. Kanellopoulou, and P. G. Koutsoukos, "Membrane processing for olive mill wastewater fractionation," Desalination, vol. 213, no. 1-3, pp. 218-229, 2007.

[14] K. Kyriazis and V. G. Papadakis, Technoeconomical Study, Tziolas Publications, 2009. 

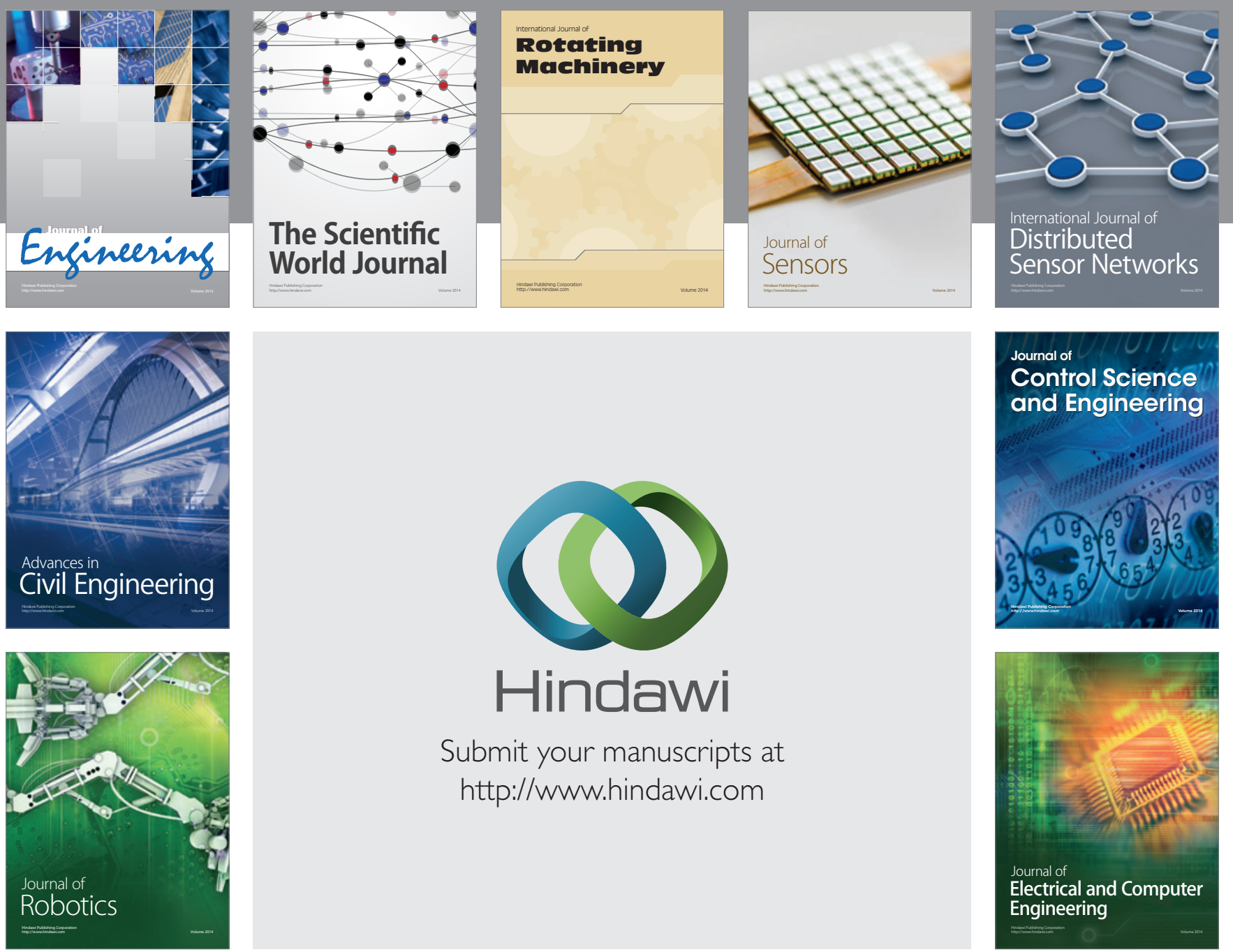

Submit your manuscripts at

http://www.hindawi.com
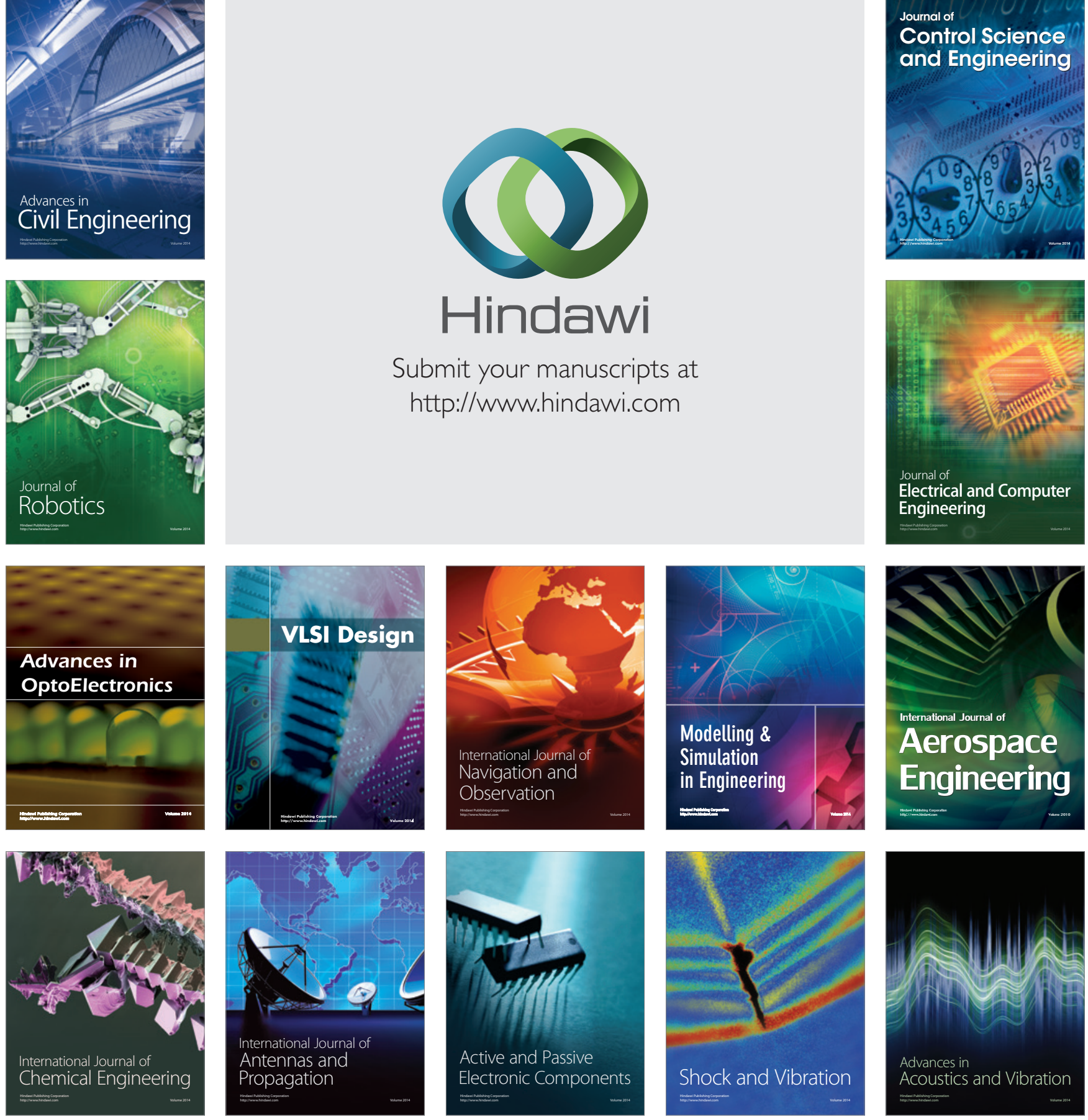